\title{
Implikasies van die kommunikatiewe handelingsteorie vir 'n prakties-teologiese \\ perspektief op die ekklesiologie
}

T F J Dreyer

Universiteit van Pretoria

\begin{abstract}
A practical theological perspective on ecclesiology as seen from the viewpoint of communicative action theory

From a practical theological perspective, this article disputes the trend in present ecclesiastical thought, abstracting a model depicting the practical functioning of the church, which is based on a single biblical metaphor. The body-of-Christ metaphor is commonly used as a church model. The eagerness to implement this construct is inspired by a paradigm shift and the incorporation of the communicative actions theory at the level of meta-theory. The hypothesis of this research is that, once the matrix of this meta-theory has been clearly identified, it must be applied to the aspects of church life. All the biblical metaphors shedding light on the functioning of the church need re-interpretation within the framework of a postmodern society and symmetrical communicative patterns. This way of constructing an ecclesiastical perspective, would lead to a more balanced church praxis.
\end{abstract}

\section{INLEIDING}

Die aanvaarding van die kommunikatiewe handelingsteorie as matriks vir die beoefening van die Praktiese Teologie (Vos 1989:187), het in die jongste tyd aanleiding gegee tot 'n lewendige debat oor en belangstelling in die ekklesiologie (vgl Pieterse 1991:3779; 1993:157-162; Burger 1991; Louw 1992; Van der Ven 1993). Hierdie hernude ekklesiologiese besinning vanuit die Praktiese Teologie is verstaanbaar omdat die metateoretiese paradigma van die kommunikatitwe handelingsteorie noodwendig konsekwensies inhou vir teorievorming op basis-teoretiese, sowel as praktyk-teoretiese vlak (Dreyer 1991:602-605). 'n Byna krampagtige soeke na die daarstelling van gemeentelike modelle om hierdie meta-teorie op die vlak van praktyk-teorievorming te verdiskonteer, het veral gekulmineer in die abstrahering van Bybelse metafore as modelle vir 
gemeentelike funksionering. Feitlik sonder teenspraak word die liggaammetafoor uitgewys as uitnemend geskik vir 'n gemeentelike model, omdat hierdie model die meeste beweegruimte bied vir die akkommodering van die kommunikatiewe handelingsteorie (vgl Heyns 1986:111-154; Pieterse 1991:80-89, 1993:159; Bäumler 1984:10; Dingemans 1986:59; Louw 1992:128; Hendriks 1992:117).

Die hipotese van hierdie studie berus op die vermoede dat die keuse van die liggaammetafoor as begronding van 'n gemeentemodel, aanleiding gee tot 'n bepaalde eensydigheid. Metaforiese spreke moet in hulle ryke verskeidenheid in ekklesiologiese besinning tot hulle reg kom, omdat elke metafoor slegs 'n poging is om in 'n sekere situasie, oor 'n bepaalde faset van kerkwees, iets te sê wat eintlik onsêbaar is. 'n Gebalanseerde ekklesiologiese perspektief sal uiteindelik moet poog om die verskillende aksente van al die metaforiese spreke oor die kerk as geloofsgemeenskap te laat meespreek. 'n Meer verantwoorde werkwyse sou wees om die grondliggende kommunikasiestyl van die kommunikatiewe handelingsteorie te identifiseer en dit as grondpatroon in alle fasette en aksente van kerkwees te vestig. Indien die kommunikasiestyl geïdentifiseer en teologies nader gekwalifiseer is, kan daar gevra word na die implikasies vir die ekklesiologie.

In die artikel sal gepoog word om kursories die grondstyl van die kommunikatiewe handelingsteorie te bepaal en dit ook as teologiese basis-teorie nader te kwalifiseer. Vanuit hierdie teologiese basisteorie sal daar gevra word na die konsekewensies vir die ekklesiologiese besinning. Dit laat die ruimte dat verskillende aksente binne 'n gemeentemodel, aan die hand van die ryke verskeidenheid van metafore, beklemtoon kan word sonder dat daar 'n eensydige keuse vir een metafoor ten koste van ander gemaak word.

\section{KOMMUNIKATIEWE HANDELINGSTEORIE}

\section{1 'n Paradigmatiese verskuiwing}

Binne die kader van akademiese gesprekvoering word daar wyd gespekuleer oor die paradigmaverskuiwing wat tans in die samelewing op evolusionêre, maar retrospektief gesien op revolusionêre wyse, gestalte begin kry.

Ons is nou in 'n oorgangstydperk wat ons beslis sal lei na 'n nuwe era, 'n nuwe geestesstroming in die wêreldgeskiedenis. Ons kan dit nie oorsién nie, ons het nie 'n behoorlike naam daarvoor nie (daarom word dit nog net as postmodern aangedui), en die kenmerke daarvan is vaag. Maar die dagbreek van hierdie nuwe tydvak het opgedaag.

(Pieterse 1993:15) 
Van Aarde (1990:300) wys daarop dat dit nie maklik is om die begrip 'postmoderniteit' te definieer nie en of hierdie begrip die regte omskrywing is van die denkstruktuur wat besig is om vorm aan te neem nie. Feit is dat hierdie paradigmaverskuiwing reeds wetenskapsbeoefening in die algemeen, maar ook teologiese nadenke in die besonder, radikaal beinvloed (Van Aarde 1988:49-64).

\section{2 'n Prakties-teologiese meta-teorie}

Op die terrein van die Praktiese Teologie is die omskrywing wat Firet vir die vak aanbied, naamlik die sistematiese aandag aan kommunikatiewe handelinge in diens van die evangelie (Firet 1990:612), reeds neerslag van hierdie nuwe denkpatroon. Die handelingsteoretiese benadering van die Praktiese Teologie vind op wetenskapsteoretiese vlak aansluiting by Habermas se teorie van kommunikatiewe handeling (Vos 1995:11). Daar is tans 'n groot mate van konsensus in die Nederlandse Praktiese Teologie oor hierdie benadering as paradigma vir die prakties-teologiese wetenskapsbeoefening (Höfte 1990:103; Van der Laan 1989:301-308). Peukert (1984; 1989) en Arens (1982:145-200) het baanbrekerswerk verrig om Habermas se teorie aan die vak diensbaar te maak. Hier te lande, was dit veral Pieterse (1990:41-48; 1993:53-98), wat deur sy werke hierdie wetenskapsteoretiese perspektief in die vak gevestig het en ook vir studente toeganklik gemaak het.

Dit is veral die kommunikatiewe handelingsteorie van Habermas wat, soos Pieterse (1993:96) tereg aantoon, in die Praktiese Teologie op meta-teoretiese vlak funksioneer. Die fokus van hierdie ondersoek val nie primêr op die ontwikkelingsgeskiedenis van die teorie totdat dit sy uiteindelike gestalte as meta-teorie in die vak gevind het nie. Pieterse (1993:53-98) gee 'n grondige weergawe van die agtergronde en faktore wat die denke van Habermas en sy teorie beïnvloed het. Hier word veral gevra na die implikasies wat so 'n meta-teorie vir 'n prakties-teologiese besinning oor die ekklesiologie, sal inhou. Vos (1995:14) vat die essensie van kommunikatiewe handelinge soos volg saam:

Kommunikatiewe handelinge vind in lewenswêrelde plaas wat vir mekaar poreus deurdringbaar is. Mense soek in kommunikatiewe handelinge na begrip vir mekaar se standpunte, en as dit kan na ooreenstemming. Kommunikatiewe handelinge is gerig op ontmoetings. In die verhoudings word subjek-subjek relasies gevestig. In kommunikatiewe handelinge behandel mense mekaar op gelyke voet en hulle aanvaar mekaar as gelyke gespreksgenote.

(Vos 1995:14) 
Kommunikatiewe handelinge druk dus die totale omgang, verhouding, reaksie en optrede in woord en daad tussen gelowiges uit. Dit lê klem op 'n vrye gelykwaardige en op Verständigung gerigte optrede, in teenstelling tot strategiese en instrumentele handelinge wat op mag gerig is en mense misbruik, afhanklik stel, onderduk en tot konflik en stryd lei (Pieterse 1993:7). Kommunikatiewe handelinge het dus ten doel om onderlinge begrip, konsensus oor die normatiewe betekenis van die Skrif en die optrede daarvolgens te bewerk (Pieterse 1993:9). Die grondpatroon van hierdie kommunikatiewe handelinge vind plaas in 'n simmetriese kommunikasiestyl wat ruimte bied vir vryheid, gelykheid en onvoorwaardelike aanvaarding. In sy wese is daar binne hierdie benadering nie ruimte vir manipulering, uitbuiting en outoritêre optrede nie. Dit beoog die ideaal van ' $n$ heersersvrye kommunikasie waar mense binne relasies vrywillig tot deelname, betrokkenheid en koinonia verbind raak. Habermas se teorie is vir sy realisering in die praktyk afhanklik van sy normatiewe uitgangspunt van die ideale kommunikasiesituasie, die Herrschaftsfreie Kommunikation. Dit gaan om 'n ideaal wat hier nêrens verwesenlik kan word nie, maar tog ook nie net 'n wensdroom is nie (Pieterse 1993: 132).

Pieterse laat dit na om ook kritiek op Habermas se 'utopiese ideologie' uit te oefen (vgl Van Aarde 1994:11). Van Aarde (1995a:19) spreek kritiek uit teen die feit dat Habermas die 'estetiese rede', dit wil sê die affektiewe dimensie van menswees, ten koste van die 'praktiese rede', dit wil sê die handelingsdimensie van menswees, onderbeklemtoon. Die paradigmaverskuiwing vra ook na die bewustelike verdiskontering van die pragmatiese en die affektiewe/estetiese in relasie met die kognitiewe.

Opsommenderwys kan die belangrikste eienskappe van die paradigmaverskuiwing vanaf modernitiet na postmoderniteit, asook die kommunikatiewe handelingsteorie en die implikasies wat dit vir die Praktiese Teologie as vak en vir die funksionering van die gemeente inhou, soos volg saamgevat word:

* Die Praktiese Teologie hou hom besig met die verstaan en verklaar van kommunikatiewe geloofshandelinge in diens van die evangelie - geloofshandelinge wat Christene uitvoer omdat hulle in Jesus Christus glo; hierdie handelinge kan omskryf word aan die hand van 'n paar trosbegrippe soos: prediking, onderrig, sorg, viering en diens (Pieterse 1990:15);

* daar is een handeling wat grondliggend aan alle ander handelinge funksioneer, en dit is kommunikasie (Firet 1987:260); die handelinge van prediking, onderrig, sorg, viering en diens is wesenlik kommunikatief, omdat die Christelike geloof daarin oorgedra en opgebou word;

* die kommunikatiewe handelingsteorie vereis 'n simmetriese kommunikasiepatroon; dit lê klem op vrye, gelykwaardige, nie-outoritêre optrede wat mense vrywaar teen magsmisbruik en instrumentele manipulasie; 
* die gees van hierdie meta-teorie is 'n liefdevolle, offervaardige, solidêre diensvaardige omgang van gelowiges met mekaar (Pieterse 1993:7);

* kommunikatiewe handelinge het dus ook ten doel om onderlinge begrip en konsensus oor die normatiewe betekenis van die Skrif en die optrede daarvolgens te bewerk (Pieterse 1993:8);

* Bäumler (1974) gaan selfs so ver om die koninkryk van God te verstaan as die ryk van heil waarin vrede, geregtigheid en vryheid heers as die teologiese siening van onverstoorde kommunikasie tussen mense; hierdie siening van die koninkryk bied genoegsame ruimte vir die emansipatoriese belang van kommunikatiewe handelinge - dit het die doelwit van verandering ter bereiking van die ideaal van 'n samelewing vry van verwronge kommunikasie. Sodoende word die blokkades in kommunikatiewe handelinge blootgelê en opgehef binne 'n emansipatoriese praxis (Höfte 1990:38);

* die werk van die Heilige Gees binne 'n handelingsteoretiese opvatting maak die verlegging van die grense van die kommunikatiewe kompetensie in die rigting van 'n oop, regverdige en kommunikatiewe gemeenskap veel meer moontlik (Van der Ven 1990:58-67); en

* die affektiewe dimensie van menswees in relasie met die kognitiewe, asook 'n doelbewuste werklikheidsbetrokkenheid, sal in kommunikatiewe geloofshandelinge weerspieël moet word.

\subsection{Teologiese kanttekeninge}

Daar is al vantevore daarop gewys dat hierdie teorie op meta-teoretiese vlak vanuit teologiese basisteorieë nader gekwalifiseer moet word (Dreyer 1991:602-605). 'n Onkritiese oorname van meta-teorieë kan myns insiens die teologiese karakter van die vak en die perspektief op die kerk ernstig skaad. Die inkorporering van die kommunikatiewe handelingsteorie op meta-teoretiese vlak vra dus dat die Praktiese Teologie as teologiese dissipline sekere kernbegrippe met teologiese inhoude sal vul. Aan die hand van die bogenoemde samevatting van die belangrikste implikasies van hierdie teorie, kan die volgende teologiese kanttekeninge daarby in gedagte gehou word.

Die feit dat die studieveld van die Praktiese Teologie in terme van kommunikatiewe geloofshandelinge beskryf word, is 'n wins - gesien vanuit die kerklike praxis. Met hierdie benadering is afskeid geneem van die diakonologiese benadering of amptelike vakke wat die gemeentelike funksionering laat opgaan in die funksionering van die ampte. In hierdie benadering geld die Skrif as enigste kenbron. Die klem val dan op die bestudering van die ampte en die dienste wat deur die ampsdraers uitgevoer moet word. Die gewone lidmate en hulle rol in die kerk het nie in die verlede genoeg- 
saam in die fokus gekom nie (Pieterse 1993:104; Burger 1991:59-60). Kommunikatiewe geloofshandelinge open die veld vir die funksionering van die kerk as geloofsgemeenskap (wat alle lidmate insluit), sowel binne die ruimte van die erediens en kerklike aktiwiteite, met die oog op die lewe van gelowiges in die kader van die breë gemeenskap. Soos reeds betoog (Dreyer 1991:602-605) is die nadere kwalifisering van kommunikatiewe geloofshandelinge, as 'in diens van die evangelie', te vaag omlyn. Uiteindelik sal daar nie slegs op 'n empiriese wyse binne 'n plurale samelewing uitgemaak kan word wat 'in diens van die evangelie' is nie. Kommunikatiewe geloofshandelinge van die geloofsgemeenskap sal voortdurend genormeer moet word vanuit die geloofsrelasie tussen God en mens soos betuig in die Skrif. Met hierdie nadere kwalifisering open kommunikatiewe geloofshandelinge nuwe perspektiewe vir die ekklesiologiese besinning.

Dat kommunikasie die grondliggende handeling is waardeur alle modi van geloofshandelinge voltrek word, word deur die kommunikatiewe handelingsteorie as sine qua non beklemtoon. Dit onderstreep die feit dat oordrag van die evangelie nie anders plaasvind as deur kommunikatiewe handelinge nie. Die kerk sal dus sensitief moet wees vir die kommunikasiestyl wat binne ' $n$ bepaalde era (postmoderne) die mees aanvaarbare en effektiewe blyk te wees. As 'n simmetriese kommunikasieverhouding in 'n postmoderne era 'n gegewe is, sal die kerk sy kommunikatiewe geloofshandelinge sover moontlik binne 'n simmetriese verhouding moet voltrek. Hierdie vereiste vir steuringsvrye kommunikasie vra egter ook om nadere teologiese kwalifisering. In prediking, sorg en onderrig vind die oordrag van geloof nie anders plaas as binne interpersoonlike verhoudings nie. In hierdie interpersoonlike verhoudings geld die eis onverkort dat daar 'n simmetriese kommunikatiewe grondhouding moet wees. Selfs in die prediking, wat in die vorm van 'n monoloog plaasvind, sal die styl van die prediker hierdie simmetriese verhouding in geantisipeerde dialoog weerspieël. 'n Verwronge ampsbeskouing wat 'n outoritêre, asimmetriese en manipulerende houding by talle ampsdraers gekweek het en uitgemond het in 'n eenrigtingverkeer, sal moet plek maak vir ' $n$ simmetriese kommunikasieverhouding met gelykheid en vrye wisseling van dialoogrolle. Teologies gesien, is so ' $\mathrm{n}$ grondhouding nader aan die oorspronklike bedoeling van die Bybelse diakonia, wat juis die dienskarakter beklemtoon. Tog is daar bepaalde teologiese reserwes. Roscam Abbing (s a:20) sê dat dit in die pastorale gesprekke om 'n 'altergesprek' gaan. Dit gaan om die belang van 'n ander persoon met die oog op 'n heel spesifieke inhoud: die Woord van God. Hierdie oriëntasie aan die Woord van God verskaf aan die gesprek altyd 'n asimmetriese karakter. Die feit dat die Woord en die Gees ' $n$ derde faktor in die pastorale gesprek (en in alle geloofskommunikasie) is, stempel die dialoog in die gepsrek tot 'n trialoog (Louw 1993:246). 
In die relasie tussen God en mens, wat via kommunikatiewe geloofshandelinge van mense in 'n hermeneuties-pneumatiese Woord-gebeure gestalte kry, breek die asimmetriese verhouding deur as die mens voor die gans andere God te staan kom en coram Deo lewe.

Die bedoeling van hierdie meta-teorie om 'n liefdevolle, offervaardige, solidêre diensvaardige omgang van gelowiges met mekaar te bewerkstellig, is 'n aksentuering van die koinonia en die diakonia wat in die kerk verwaarloos geraak het. Tog is hierdie liefde en solidariteit, teologies gesien, weer eens gestempel en genormeer (Louw 1993:182-185).

As Pieterse (1993:8) stel dat kommunikatiewe handelinge ook ten doel het om onderlinge begrip en konsensus oor die normatiewe betekenis van die Skrif en die optrede daarvolgens te bewerk, sal daar tog ook teologiese reserwes moet geld. Hierdie formulering pas goed in by hedendaagse kenteorieë, maar is teologies gesien tog gevaarlik. Natuurlik sal die normatiewe betekenis van die Skrif by wyse van kommunikatiewe handelinge, ideaal-gesproke, soveel makliker geinternaliseer word as dit langs die weg van konsensus bepaal kan word. In 'n sekere sin is die belydenis van die kerk hierdie konsensus van die geloofsgemeenskap. Die basis van hierdie belydenis is egter nie primêr geleë in konsensus nie, maar in die aanspraak van God wat telkens in die Woord-gebeure gesagvol tot die mens spreek. Dit sou vir die kerk en teologie 'n kwade dag wees as blote konsensus, soos bereik in kommunikatiewe handelinge en diskoers (akademiese gemeenskap), die normatiewe betekenis van die Skrif moet bepaal.

As die koninkryk van God verstaan word as die teologiese siening van onverstoorde kommunikasie tussen mense en as dit gelykgestel word aan die ideale ruimte vir verandering binne 'n emansipatoriese praxis, beroof dit die koninkryk en die eskatologiese verwagting van sy Christologies-soteriologiese onderbou. Dat die deelwees van die koninkryk van God duidelike emansipatoriese motiewe impliseer, is vanselfsprekend - maar dan gekwalifiseerd vanuit die relasie God en mens, tot opbou van die liggaam van Christus. Verandering op sigself het teologies geen waarde as dit nie voortspruit en getemper word deur die Bybelse metanoia nie (Louw 1993:144-147). Hierdie meta-teoretiese benadering moet die kerk weer opnuut wys op sy taak in die breër gemeenskapslewe om deur sy kerkwees die gemeenskap bewus te maak, en waar moontlik selfs te bevry van diskriminasie, magsmisbruik en uitbuiting - maar dan alleen as 'n moontlikheid wat 'n werklikheid kan word waar die mens deel kry aan die nuwe lewe in Jesus Christus.

Die eis om in 'n postmoderne era ook die affektiewe dimensie van menswees in relasie met die kognitiewe te beklemtoon, is teologies gesien 'n welkome vernuwing. Enersyds bevry dit die verkondiging van 'n dorre intellektualisme en dogmatisme, maar 
andersyds, indien die affektiewe in relasie met die kognitiewe beklemtoon word, vrywaar dit die verkondiging van 'n oppervlakkige emosionaliteit. Die onderlinge verband en interafhanklikheid van die indikatief, imperatief en beloftes in die kerugma is hier van belang, omdat dit in 'n sekere sin die kognitiewe, konatiewe en affektiewe dimensies van menswees reflekteer (Dreyer 1994:285-291). Die eis om werklikheidsbetrokkenheid, wat iets anders is as blote pragmatisme, is van wesenlike belang vir die aktuele verkondiging van die evangelie (Dreyer 1989:366).

\section{METAFORE EN MODELLE}

Die insigte van die kommunikatiewe handelingsteorie het die dringendheid vir ekklesiologiese besinning vanuit 'n prakties-teologiese perspektief al meer in die fokus gebring. Bestaande ekklesiologiese teorieë lê eensydig klem op teologiese insigte wat die uitsig op die empiriese kant verdof. Pieterse (1993:158) pleit vir die daarstel van 'n ekklesiologie vanuit 'n prakties-teologiese perspektief. Hierdie perspektief het veral twee gesigspunte, naamlik 'n kommunikatiewe perspektief en die fokus op die funksies van die kerk. Soos reeds vroeër vermeld, stimuleer hierdie vertrekpunt die soeke na 'n model waarbinne die funksies van die kerk in 'n kommunikatiewe raamwerk optimaal sal realiseer. Daar is redelike konsensus dat die liggaam-van- Christus-model as metaforiese verstaan van die kerk die mees geskikte is binne die huidige konteks.

Dit is 'n model waarin simmetriese kommunikasie geskied tussen alle lede van die gemeente. Dit is ' $n$ model waarin die opboumotief sentraal staan ... Dit is 'n model waarin groepsbediening tot sy reg kan kom. Dit is 'n model wat geestelike volwassenheid en spiritualiteit ten doel het. Dit is 'n model wat vanweë sy simmetriese kommunikasie en groepsgestruktureerdheid ruimte bied vir diepgaande koinonia en eenheid in liefde. Dit is ook 'n model wai sigself as deel van die samelewing sien en sosiaal en polities ruimte skep vir die gemeente se taak in die samelewing.

(Pieterse 1993:160)

Wanneer ' $n$ bepaalde Bybelse metafoor tot model verhef word, beteken dit by implikasie dat ander metafore wat ook 'n bydrae kan lewer tot die verstaan van die wese en funksionering van die kerk, op die agtergrond geskuif word. Die keuse van die liggaammodel is in 'n sekere sin 'n reaksie teen die eensydige gebruik van die herdermetafoor as kerkmodel. Hierdie eensydige gebruikmaking van die herder-kudde-model is, restrospektief gesien, waarskynlik die neerslag van kontekstuele beïnvloeding. In 'n verbygegane era waar ' $n$ outoritêre styl, magsmisbruik, eenrigting-asimmetriese kom- 
munikasie en 'n diktatoriale houding aanvaarbaar was, het die herder-kudde-model goed gefunksioneer. As ons uit die lesse van die geskiedenis wil leer, moet ons nie weer in dieselfde slaggat trap om in ' $n$ nuwe era in 'n nuwe eensydigheid te verval nie. Bybelse metafore is komplementêr tot mekaar en moenie op grond van ' $n$ sekere gegewe konteks van die kerk, teen mekaar afgespeel word nie.

Waarskuwende klanke oor die eensydige gebruik van kerkmodelle, as abstrahering van Bybelse metafore, om meta-teoretiese vertrekpunte te fasiliteer, is by die 1995 kongres van die Werkgemeenskap vir Praktiese Teologie in Suid-Afrika gehoor (Erasmus 1995). Erasmus grens hom af teen die neiging om 'n ekklesiologie vanuit die funksies van die kerk en die kommunikatiewe handelingsteorie te ontwerp, omdat dit nie rekening hou met die wese van die kerk soos gereflekteer in die Skrif nie. Sy besware is wel legitiem, indien die grondpatroon van hierdie meta-teorie nie vanuit die teologie nader gekwalifiseer word nie. Soos reeds in hierdie artikel betoog, is dit essensieel vir die behoud van die teologiese kwaliteit van die vak. Hy wys egter ook tereg op die gevaar dat die keuse van metafore as begronding vir 'n gemeentemodel eklekties met die Skrif omgaan, omdat ander perspektiewe uit die oog verloor word. By dieselfde geleentheid het Burger (1995) daarvoor gepleit dat die familiale metafoor in die ekklesiologiese besinning weer uit die vergetelheid opgediep moet word omdat dit opwindende moontlikhede inhou. Sy gedagtes verraai ook' $n$ sekere ongemak met die feit dat daar eenogig na die liggaammetafoor gekyk word. Die vraag ontstaan of dit ' $n$ verantwoordelike werkwyse is om 'n Bybelse metafoor in isolasie as model vir die funksionering van die kerk te gebruik (of te misbruik). Om dié vraag te beantwoord moet daar kortliks gekyk word na die metafoor as kommunikatiewe fenomeen in Bybelse literatuur.

\subsection{Metaforiese spreke}

'n Metafoor is 'n taalverskynsel waarin een 'ding' gesien word as iets anders, om voor te gee dat hierdie daardie is, omdat ons eintlik nie weet om oor hierdie te praat nie en daarom maak ons van daardie gebruik om oor hierdie te praat (McFague 1983:15; vgl Van Aarde 1995b:42). As 'n wyse van spreke maak ons gebruik van die een waarvan ons meer weet om iets meer te sê van die een van wie ons minder weet of selfs niks van weet nie (Van Aarde 1995b:43). 'n Metafoor is dus 'n poging om na analogie van die bekende iets oor die onbekende te sê. Dit spreek dus vanself dat 'n analogie nie die onbekende volledig verklaar of verduidelik nie. Elke metafoor beklemtoon ' $n$ bepaalde faset van die onbekende aan die hand van die bekende. Die saak wat metafories verduidelik word, is dus nie volledig vervat in die metafoor self nie, maar is veel groter en omvattender as die een faset wat die metafoor wil of kan belig. Om die betekenis van 
die metafoor te bepaal moet ons ook onthou dat 'n metafoor telkens in konteks verstaan moet word (Van Aarde 1995b:43). In een konteks sal daar byvoorbeeld onder herderskap iets anders verstaan word as in ' $n$ ander konteks. Dit is daarom te verstane dat ons in die Bybelse getuienis oor die funksionering van die geloofsgemeenskap 'n ryke verskeidenheid metafore aantref (herder-kudde; liggaam; gebou van God; wingerdstok en lote; familiale; arbeiders in wingerd; sout; suurdeeg; lamp en talle ander). Elkeen van hierdie metafore het ten doel om met gebruikmaking van 'n bepaalde bekende beeld ' $n$ belangrike faset van kerkwees te belig. In 'n ekklesiologiese perspektief vanuit die funksionering van die kerk, sal daar dus gepoog moet word om al die fasette soos belig deur die verskillende metafore, te inkorporeer.

\subsection{Abstrahering van modelle}

Die keuse van ' $n$ bepaalde metafoor as basis vir 'n gemeentemodel moet noodwendig daartoe lei dat die aspek of aspekte waarop die metafoor klem lê, in die model eensydig geaksentueer word ten koste van ander aksente soos deur ander metafore belig. Die herder-kudde metafoor wat in die verlede bewustelik of onbewustelik as model vir die funksionering van die gemeente gegeld het ( $\mathrm{vgl}$ die bevestigingsformulier vir dienaars van die Woord en ouderlinge), het daartoe aanleiding gegee dat die rol en taak van ampsdraers oorbeklemtoon is ten koste van die lidmate (waarskynlik omdat 'n bepaalde lewensklimaat hierdie model gefasiliteer het). In dieselfde mate lei die eensydige keuse van die liggaamsmodel tot ' $n$ verabsolutering van die plek en funksie van die lidmate (omdat die postmoderne era daarom vra). Dit is natuurlik reg dai die konteks en tydsgees moet meespreek in die praxis van die geloofsgemeenskap, maar dan nie tot so 'n mate dat dit voorskriftelik word in die vasstelling van die wesenlike elemente wat noodsaaklik is vir die funksionering van die gemeente nie. Juis daarom is dit belangrik dat die huidige era sover as moontlik geakkommodeer word, maar dan in soverre as wat al die metaforiese spreke oor die kerk in daardie grondparadigma ingetolk kan word. As die grondpatroon of matriks van die postmoderne era geïdentifiseer is, moet daar gevra word of, en indien wel hoe, hierdie grondpatroon in elke faset van die funksionering van die kerk tot sy reg kan kom? Sodoende sal daar 'n meer gebalanseerde visie op die funksionering van die kerk gevorm kan word.

Ter illustrasie van die argument kan byvoorbeeld aangetoon word dat die herderkudde metafoor nie noodwendig impliseer dat daar ' $n$ asimmetriese kommunikasiestyl, of 'n outoritêre magsmisbruik en onbetrokkenheid van lidmate hoef te wees nie. Die doel van die herder-metafoor is om iets te probeer sê oor die verantwoordelikheid van die geestelike leier, sonder om te wil beweer dat die lidmaat passief en onbetrokke moet wees. In sy oorspronklike konteks wek die herder-metafoor juis nie die konnota- 
sie van outoritêre magsmisbruik nie. Louw (1993:25) betoog tereg dat die herdermetafoor die liefdevolle styl van die pastor wil beklemtoon. Dit wil die unieke betekenis van die pastorale sorg as deernisvolle en liefdevolle barmhartigheid verbind met Jesus Christus se opofferende en verlossende liefde. Die pastor verbeeld op 'n konkrete wyse God se sorgsame bystand aan die mens in nood. Uit hierdie enkele opmerkings is dit duidelik dat die herdermetafoor in 'n nuwe konteks verwring is, mede as gevolg van 'n bepaalde lewensklimaat wat as katalisator vir die verwringing gedien het.

Dit is ook opmerklik dat die liggaammetafoor tans gewild is, omdat dit ruimte bied vir die aktivering en deelname van lidmate, elkeeen met sy besondere gawes. Hierdie betekenis wat uit die metafoor afgelei word en in 'n gemeentemodel beklemtoon word, is al klaar 'n distorsie van die oorspronklike bedoeling van die metafoor soos dit byvoorbeeld in 1 Korintiërs 12 funksioneer. In die gemeente was dit juis die probleem dat individuele gelowiges hulle te veel op hulle persoonlike gawes beroem het, en dit in die gemeente op só 'n wyse beoefen het dat dit die eenheid en wesenlike funksionering van die gemeente begin skaad het. In die lig daarvan gebruik Paulus die beeld van die liggaam om die beoefening van individuele gawes te temper met die oog op die welwees van die liggaam as geheel.

Bogenoemde voorbeelde is genoegsame bevestiging van die vermoede dat die abstrahering van 'n gemeentemodel op grond van één metafoor tot 'n eensydige perspektief lei. Die erns maak met die postmoderne lewensklimaat en die konsekwensies van die kommunikatiewe handelingsteorie kan nie langs die weg van die verabsolutering van 'n metafoor tot gemeentemodel realiseer nie. Veeleer moet daar gepoog word om op grond van die grondpatroon, styl en lewensklimaat van die postmoderne era te vra na die konsekwensies wat dit vir die verskillende aspekte van kerkwees inhou. Daar moet doelbewus gesoek word na maniere om dit in die kerklike praxis te integreer.

\section{EKKLESIOLOGIESE PERSPEKTIEF}

Die beskrywing van die kerklike funksionering aan die hand van kommunikatiewe geloofshandelinge moet ons in ekklesiologiese besinning daartoe bring om rekening te hou met al die geloofshandelinge en handelingsvelde (Heyns \& Pieterse 1990:14-15). Binne die gereformeerde tradisie, met die sterk beklemtoning van die Woordteologie, het die neiging ontstaan om in die kerklike praktyk geloofshandelinge te reduseer tot prediking en handelingsvelde te beperk tot die erediens. Die primaat van die prediking en die erediens as sentrum van die geloofslewe het veroorsaak dat verkondiging in die prediking gemonopoliseer is en die geloofslewe begrens is tot die mure van die kerkgebou. Doelbewuste beplanning om geloofshandelinge weer in onderrig, sorg, viering en diens te aktiveer moet op die voetsoolvlak van lidmate tot sy reg kom. 'n Beperkte 
visie wat lei tot die formulering van handelingsvelde in geykte begrippe, begrens deur 'n na-binne-gerigtheid, moet plek maak vir die ontginning van nuwe handelingsvelde in die ruimte van die kerk en die breër gemeenskap.

Burger (1994:88) is waarskynlik reg as hy sê dat ons die prediking totaal oorvra het. Die prediking moes alles doen - ons het alles van die prediking verwag, maar intussen relativeer die struktuur of ordening van die gemeente alles wat gepreek word. Ons verkondig die noodsaak van koinonia, diakonia, getuienis van die evangelie maar intussen bevestig die gebrek aan die nodige strukture om dit te kanaliseer, 'n teenoorgestelde boodskap. Effektiewe leer in die geloofsgemeenskap vind nie slegs volgens 'n intellektuele model plaas nie, maar deur wat genoem sou kan word: sosialisering (Burger 1994:88). Die geloofsgemeenskap moet in die wêreld 'n sigbare alternatiewe gemeenskap wees waar deur onderlinge sorg hierdie waardes voorgeleef en geinternaliseer word.

'n Simmetriese kommunikatiewe grondhouding moet in alle fasette van kerkwees gevestig word. Juis in 'n bereidheid om die ander volledig as gelyke te aanvaar; 'n openheid om eerlik na ander se menings te luister; die aanvaarding van die risiko om in dialoog mekaar te lei tot konsensus oor die norme van die Skrif; 'n onopgesmukte egtheid en spiritualiteit - dit alles vorm die ruimte waarbinne die woordgebeure van die gans andere God deur sy Gees gestalte kry en op mense se lewens beslag lê. Dit maak nie die prediking oorbodig nie, maar beklemtoon juis die primaat van die prediking in die lewe van die geloofsgemeenskap.

\section{Literatuurverwysings}

Arens, E 1982. Kommunikative Handlungen: Die paradigmatische Bedeutung der Gleichnisse Jesu für eine Handlungstheorie. Düsseldorf: Patmos.

Bäumler C 1974. Praktische Theologie: Ein notwendiges Element der wissenschaftliches Theologie. Evangelische Theologie 28, 25-55.

- 1984. Kommunikative Gemeindepraxis. München: Kaiser.

Burger C 1991a. Praktiese Teologie in Suid-Afrika: 'n Ondersoek na die denke oor sekere voorvrae van die vak. Pretoria: RGN.

- 1991b. Die dinamika van 'n Christelike geloofsgemeenskap. Kaapstad: Lux Verbi.

- 1995. Die kerk as familie van God - 'n verwaarloosde metafoor? Ongepubliseerde referaat gelewer tydens die vergadering van die Werkgemeenskap vir Praktiese Teologie in Suid-Afrika, Januarie 1995.

Dingemans, G J D 1986. In de leerschool van het geloof. Kampen: Kok. 
Dreyer, T F J 1989. 'n Poging tot 'n herdefinisie van die prediking binne die raamwerk van die Reformatoriese teologie. HTS 45, 350-369.

- 1991. Eerste treë in die Praktiese Teologie - waarheen? HTS 47, 597-608.

- 1994. Die kerugmatiese struktuur as bolwerk teen moralisme in die prediking. HTS 50, 281-295.

Erasmus, L M 1995. 'Sola Ecclesia' — 'n kritiese vraagstelling na aanleiding van die kerkbegrip van die gemeentebouteologie in die Nederduitse Gereformeerde Kerk. Ongepubliseerde referaat gelewer tydens die vergadering van die Werkgemeenskap vir Praktiese Teologie in Suid-Afrika, Januarie 1995.

Firet, J 1987. Spreken als een leerling: Praktisch-theologische opstellen. Kampen: Kok.

- 1990. Enkele actuele thema's in de praktische theologie. Praktische Thelogie 17, 608- 625 .

Hendriks, H J 1992. Strategiese beplanning in die gemeente: Beginsels en praktyk van gemeente vernuwing. Wellington: Hugenote Uitgewers.

Heyns, L M 1986. 'n Prakties-teologiese ondersoek na die kerklike strukture van die Nederduitse Gereformeerde Kerk. DTh-proefskrif, Universiteit van Suid-Afrika.

Höfte, B 1990. Bekering en bevrijding: De betekenis van de Latijns-Amerikaanse theologie voor een praktisch-theologische basistheorie. Hilversum: Gooi \& Sticht.

Louw, D J 1992. Die ontwerp van 'n prakties-teologiese ekklesiologie vir gemeentebou. Praktiese Teologie in Suid-Afrika 7, 119-136.

- 1993. Pastoraat as ontmoeting. Pretoria: RGN.

McFague, S 1983. Metaphorical theology: Models of God in religious language. London: SCM.

Peukert, H 1984. Was ist eine praktische Wissenschaft? Handlungstheorie als Basistheorie der Humanwissenschaft: Anfragen an die Praktische Theologie, in Fuchs, O (red), Theologie und Handeln: Beiträge zur Fundierung der Praktischen Theologie als Handlungstheorie. Düsseldorf: Patmos.

- 1989. Kommunikatives Handeln, Systeme der Machtseigerung und die unvollendeten projekte Aufklärung und Theologie, in Arens, E (red), Habermas und die Theologie: Beiträge zur theologischer Rezeption, Diskussion und Kritik der Theorie kommunikativen Handelns. Düsseldorf: Patmos.

Pieterse, H J C \& Heyns, L M 1990. Eerste treë in die Praktiese Teologie. Pretoria: Gnosis.

- 1991. Gemeente en prediking. Pretoria: NGKB.

- 1993. Praktiese Teologie as kommunikatiewe handelingsteorie. Pretoria: RGN.

Roscam Abbing, P J s a. Gespreksbeleid in de pastorale zorg. Utrecht: Bijleveld. 
Roscam Abbing, P J s a. Gespreksbeleid in de pastorale zorg. Utrecht: Bijleveld.

Van Aarde, A G 1988. Historical criticism and holism: Heading toward a new paradigm?, in Mouton, J, Van Aarde, A G \& Vorster, W S (eds), Paradigms and progress in theology, 49-64. Pretoria: HSRC.

- 1990. Holisme as 'n postmodernistiese filosofie in teologiese lig. HTS 46, 293311.

- 1994. The epistemic status of the New Testament and the emancipatory living of the historical Jesus in engaged hermeneutics. Neotestamentica 28/2, 1-25.

- 1995a. Kerk en teologie op pad na die derde millenium: 'n Paradigmatiese verskuiwing van middelmatige aard. HTS 51, 13-38.

- 1995b. Kerk en teologie op pad na die derde millenium: Gedagtes oor die kontekstualisering van die dialektiese teologie in 'n plurale samelewing. HTS 51, 3964.

Van der Laan, J H 1989. Ernst Lange en de prediking. Kampen: Kok.

Van der Ven, J A 1990. Entwurf einer empirischen Theologie. Kampen: Kok.

- 1993. Ecclesiologie in context. Kampen: Kok.

Vos, C J A 1989. Die evangelie as pragmaties-kommunikatiewe gebeure: 'n Perspektief op evangelistiek. Skrif en kerk 10, 183-190.

- 1995. Die blye tyding. Pretoria: RGN. 